\title{
New data on the morphology and systematic status of Spinitectus petrowi and Spinitectus gigi (Nematoda: Cystidicolidae) parasitic in catfishes in central China
}

\author{
František Moravec ${ }^{1}$, Pin Nie $^{2}$ and Guitang Wang ${ }^{2}$ \\ ${ }^{1}$ Institute of Parasitology, Academy of Sciences of the Czech Republic, Branišovská 31, 37005 České Budějovice, Czech \\ Republic; \\ ${ }^{2}$ State Key Laboratory of Freshwater Ecology and Biotechnology, and Laboratory of Fish Diseases, Institute of Hydrobiology, \\ Chinese Academy of Sciences, Wuhan 430072, Hubei Province, P. R. China
}

Key words: parasitic nematodes, Spinitectus, freshwater fishes, Pelteobagrus, Clarias, Hubei Province, China

\begin{abstract}
Two little-known nematode species of the genus Spinitectus Fourment, 1883, S. petrowi Belous, 1965 (prevalence $25 \%$, intensity 1-8) and S. gigi Fujita, 1927 (prevalence 10\%, intensity 2-3), were collected from the gastrointestinal tract of the yellow catfish, Pelteobagrus fulvidraco (Richardson), from Liangzihu Lake, Hubei Province, central China, in September of 2002. The light and scanning electron microscopical examination of this material, supplemented by a few museum specimens of $S$. gigi collected from the catfish Clarias fuscus (Lacépède) in southern China, made it possible to study in detail the morphology of these parasite species and to redescribe them. The first species, whose correct name is $S$. petrowi Belous, 1965, exhibits some morphological features (e.g., unusually short vestibule, shape of pseudolabia and of the left spicule) not found in most other congeners; a unique feature is the presence of peculiar pairs of transversely oriented peg-like cuticular spines with rounded ends on the ventral surface of the female tail. Spinitectus gigi was found to have 28-31 cuticular spines in the first ring, relatively long distances between the 2nd-7th rings of spines, and anterior rings divided into 2 sectors; the excretory pore is located at the level of the 4th ring of cuticular spines; males posses 4 pairs of preanal- and 6 pairs of postanal caudal papillae and a pair of small phasmids. Spinitectus bagri Wang, Wu et Yu, 1993 and S. wulingensis Yu et Wang, 1997 are considered junior synonyms of $S$. petrowi, whereas S. clariasi Ky, 1971, S. ophicephali Ky, 1971 and S. yuanjiangensis Wang, Wu et Yu, 1997 are regarded to be junior synonyms of $S$. gigi. Spinitectus petrowi was not previously reported from China.
\end{abstract}

In September 2002, during investigations into the helminth parasites of fishes in central China, carried out by the Chinese-Czech research team in central China (see also Moravec and Nie 2002, Moravec and Wang 2002, Moravec et al. 2003a, b, c), numerous nematode specimens belonging to the genus Spinitectus Fourment, 1883 were collected from the yellow catfish Pelteobagrus fulvidraco (Richardson) from Liangzihu Lake, Hubei Province. These were identified as $S$. petrowi Belous, 1965 and $S$. gigi Fujita, 1927, two insufficiently described East-Asian species. This material, along with a few museum specimens of the latter species, made possible their detailed study (including scanning electron microscopy) and redescriptions of these inadequately known parasites, and their comparison with some related congeneric species. The results are presented herein.

\section{MATERIALS AND METHODS}

Specimens of both Spinitectus spp. studied were collected from the yellow catfish Pelteobagrus fulvidraco (Richardson) (20 fish examined) bought at the fish market in Wuhan (the fish originated from Liangzihu Lake $\left[30^{\circ} 05^{\prime}-30^{\circ} 18^{\prime} \mathrm{N}\right.$, $114^{\circ} 21^{\prime}-114^{\circ} 39^{\prime} \mathrm{E}$; Yangtze River basin], Hubei Province). Living specimens of fish were transported to the laboratory of the Institute of Hydrobiology, Chinese Academy of Sciences (CAS), killed and immediately examined for the presence of helminth parasites. The recovered nematodes were washed in physiological saline and then fixed in hot $4 \%$ formaldehyde solution. Because this material did not include mature females of $S$. gigi, a few specimens (1 male and 3 females) of this nematode species deposited in the parasitological collection (designated as "A 12") of the Institute of Hydrobiology, CAS, were also examined; these were collected from the whitespotted clarias Clarias fuscus (Lacépède) from Nanhai, JiuKing, southern China on 7 September 1986. For light microscopical examination, the nematodes were cleared with glycerine. Drawings were made with the aid of a Zeiss drawing attachment. Specimens used for scanning electron microscopy (SEM) were postfixed in $1 \%$ osmium tetroxide, dehydrated through a graded ethanol series, critical point dried and sputter-coated with gold; they were examined using a JEOL JSM-6300 scanning electron microscope at an accelerating voltage of $15 \mathrm{kV}$. The specimens have been deposited in the Helminthological Collection of the Institute of Parasitology, Academy of Sciences of the Czech Republic, in České Budějovice (cat. nos. N-812 - S. petrowi and N-813 - S. gigi) and in the Institute of Hydrobiology, Chinese Academy of Sciences, in Wuhan. All measurements are in millimetres unless otherwise stated. The scientific names of fishes follow Froese and Pauly (2003). 


\section{REVIEW OF SPECIES}

Family C y s t i d i c o li d a e Skryabin, 1946

Spinitectus petrowi Belous, 1965

Figs. 1-3

Syn. Spinitectus bagri Wang, Wu et Yu, 1993; S. wulingensis Yu et Wang, 1997.

Description. Small, whitish nematodes. Cephalic end rounded, posterior end conical. Surface of body with transverse rings of spines; rings interrupted at both sides of body by lateral lines (Figs. 1C, 2A); some more posterior rings incomplete. First two rings of spines usually somewhat close to each other. First ring consists of 2937 spines 0.004-0.006 long (Figs. 1C, 2A). Largest spines (0.009-0.012 long) present in anterior 2nd-9th ring (Figs. 1A, 2C); spines gradually diminishing posteriorly, smallest spines on posterior part of body. Female body with spines extending up to posterior extremity (Figs. 1J, 3C); spination of male extending posteriorly to about $1 / 2-2 / 3$ of body length. Oral aperture oval, dorsoventrally elongated, surrounded by four poorly developed, low submedian labia, two subdorsal and two subventral, with broad base, forming dorsolateral and dorsoventral margins of oral opening (Fig. 2B, D). One simple, narrow, sclerotized structure ("sublabium" in terminology of Margolis 1977), with a somewhat thickened free margin, attached by its base to inner surface of each labium. Lateral pseudolabia rather large, rounded, projecting anteriorly beyond labia. In apical view, inner parts of pseudolabia, covering partly oral opening, without usual dorsoventral expansions. Inner margins of both pseudolabia dorsoventrally straight, parallel to each other (Figs. 1D, 2B). Each pseudolabium with two elongate submedian cephalic papillae and small lateral amphid situated at its outer margin. Vestibule very short, thin-walled, with anterior part distended to form small funnel-shaped prostom in lateral view. Deirids small, situated between first and second rings of spines (Fig. 2E). Oesophagus clearly divided into anterior muscular and much longer and somewhat wider posterior portion; length ratio of both portions $1: 2.3-2.6$. Nerve ring encircles muscular oesophagus at level between second and third rings of spines. Excretory pore situated at level of fourth ring of spines (Figs. $1 B, 2 G)$. Tails of both sexes conical. Males smaller than gravid females.

Male (4 specimens): Length of body 2.679-3.631, maximum width $0.095-0.122$. Maximum length of cuticular spines 0.009 . First ring of spines situated 0.0870.090 from anterior extremity. Length of vestibule including prostom $0.012-0.018$. Entire oesophagus 0.522 0.714 long, representing $19-20 \%$ of whole body length. Muscular oesophagus 0.141-0.219 long, 0.015-0.018 wide; glandular oesophagus $0.381-0.495$ long, 0.0360.042 wide; length ratio of both parts of oesophagus $1: 2.3-2.7$. Nerve ring and excretory pore $0.120-0.129$ and $0.168-0.195$, respectively, from anterior extremity.
Testis extending anteriorly to region of glandular oesophagus. Posterior end of body ventrally curved, provided with well-developed, fairly broad subventral alae (Fig. 1G, H) reaching posteriorly end of tail. Ventral precloacal ridges (area rugosa) absent (Fig. 3D). Preanal papillae: 4 pairs of subventral pedunculate, equally spaced papillae present. Postanal papillae: 5 pairs of subventral pedunculate papillae and 1 pair of ventral sessile papillae situated just anterior to level of last subventrals (Fig. 3B). Last pair of subventral papillae followed by pair of weakly developed phasmids. Median elevated area present between 5th and 6th pairs of postanal papillae (Fig. 3B, E). Large (left) spicule $0.135-0.150$ long, markedly broad at its middle part in lateral view, with narrow, rounded distal end; length of spicule shaft $0.030-0.039$ (22-26\% of whole spicule length). Small (right) spicule 0.051-0.054 long, appearing rather variable in shape in lateral view (Fig. 1O-S), which depends on its position. Length ratio of spicules 1 : 2.6-2.8. Tail 0.078-0.090 long, with pointed tip.

Female (5 gravid specimens; measurements of 1 nongravid specimen in parentheses): Length of body 4.692-7.262 (3.672), maximum width 0.150-0.272 (0.122). Maximum length of cuticular spines 0.009 $0.012(0.009)$. First ring of spines $0.087-0.108(0.102)$ from anterior extremity. Length of vestibule including prostom $0.021-0.024$ (0.015); prostom 0.009 long and 0.012 wide. Entire oesophagus $0.762-1.110$ long, representing $15-18 \%(20 \%)$ of whole body length. Muscular oesophagus $0.222-0.312(0.225)$ long, 0.0150.030 (0.015) wide; glandular oesophagus $0.540-0.798$ (0.522) long, 0.039-0.069 (0.039) wide; length ratio of both parts of oesophagus $1: 2.4-2.6(1: 2.3)$. Nerve ring and excretory pore $0.120-0.147(0.135)$ and $0.177-$ 0.207 (0.195), respectively, from anterior extremity. Vulva not elevated, postequatorial, situated 3.155-5.032 (2.541) from anterior extremity (at 65-69\% [69\%] of body length). Vagina muscular, directed anteriorly from vulva. Amphidelphic. Fully developed eggs in uterus oval, thick-walled, smooth, larvated (Fig. 1F); size $(\mathrm{n}=$ 10) $0.036-0.042 \times 0.024-0.027$; thickness of their wall 0.003 . Tail $0.096-0.105(0.081)$ long, with small rugged appendage 0.003 (0.003) long at tip. Cuticular spines on ventral surface of tail and in region just anterior to anus mostly forming pairs, each of them situated on common, rounded outgrowth of cuticle; spines narrow, peg-like with rounded ends, oriented transversely to longitudinal axis of body (Fig. 3F, G).

H o s t: Yellow catfish, Pelteobagrus fulvidraco (Richardson) (Bagridae, Siluriformes).

Site of infection: Stomach.

L o c a 1 it y : Liangzihu Lake, Hubei Province, central China (18 September 2002).

Prevalence and intensity: $25 \%$ (5 fish infected / 20 fish examined); 1-8 (mean 3) nematodes per fish.

Comments. This species was first described as Spinitectus petrovi by Belous (1952) in her thesis on the 
A

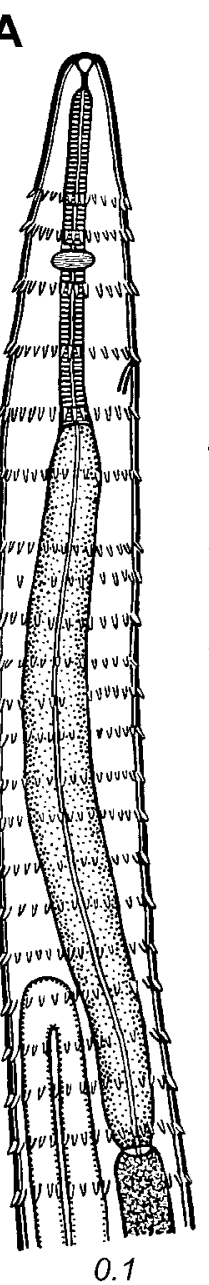

B

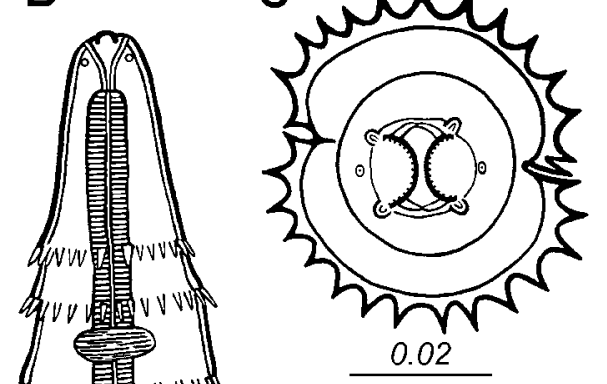

C

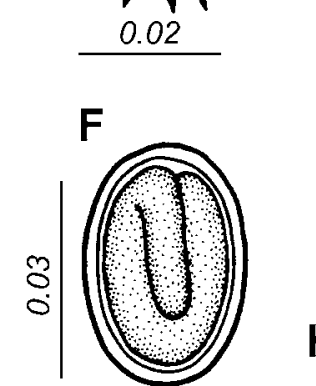

E
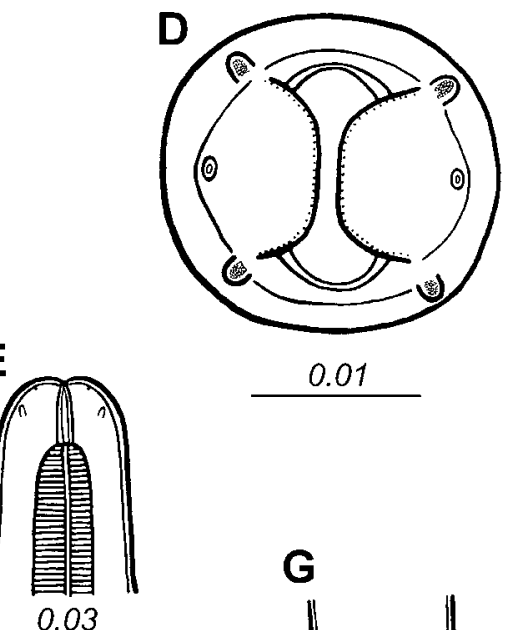

0.01

$\mathbf{G}$
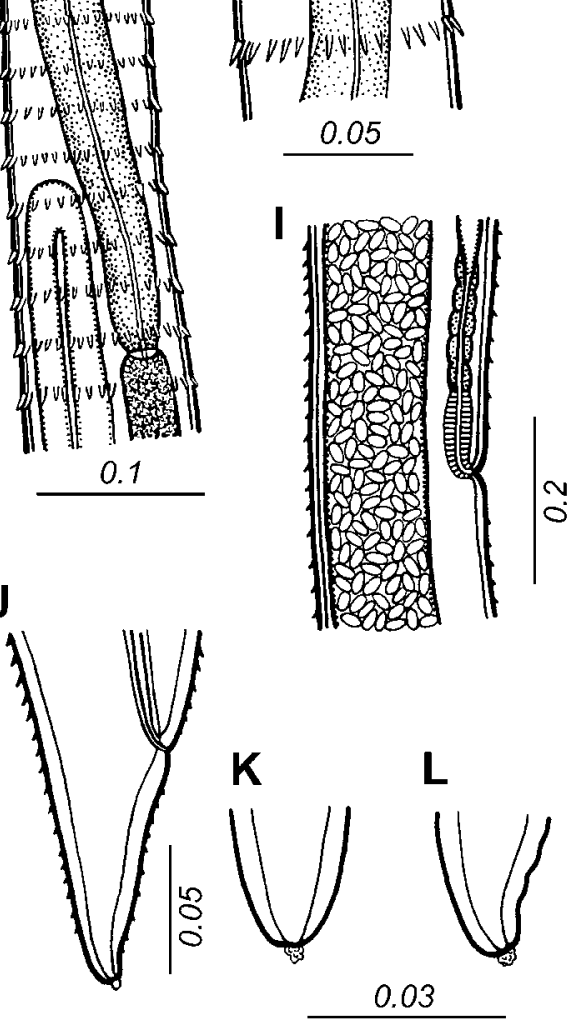

H
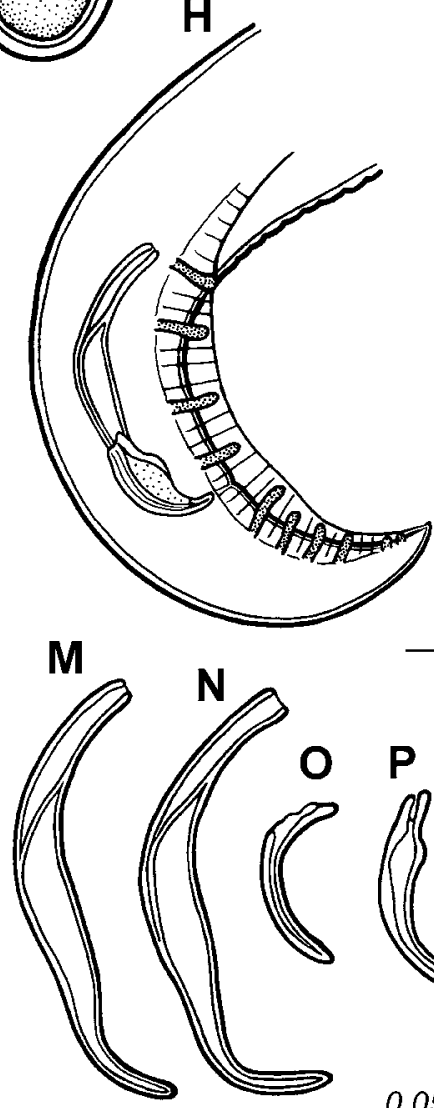
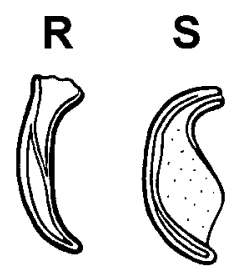

0.05

Fig. 1. Spinitectus petrowi Belous, 1965. A - anterior end of male, lateral view; B - same, larger magnification; C - cephalic end, apical view (reconstructed from scanning electron micrograph); D - mouth, apical view (reconstructed from scanning electron micrograph); E - cephalic end, dorsoventral view; $\mathbf{F}$ - fully developed egg; $\mathbf{G}, \mathbf{H}$ - posterior end of male, ventral and lateral views; I - region of vulva, lateral view; $\mathbf{J}$ - tail of gravid female, lateral view; $\mathbf{K}, \mathbf{L}$ - tail tip of female (different specimens); M, $\mathbf{N}$ - large (left) spicule, lateral views; $\mathbf{O}-\mathbf{S}$ - variability in shape of small (right) spicule, all lateral views. Scale bars in $\mathrm{mm}$. 

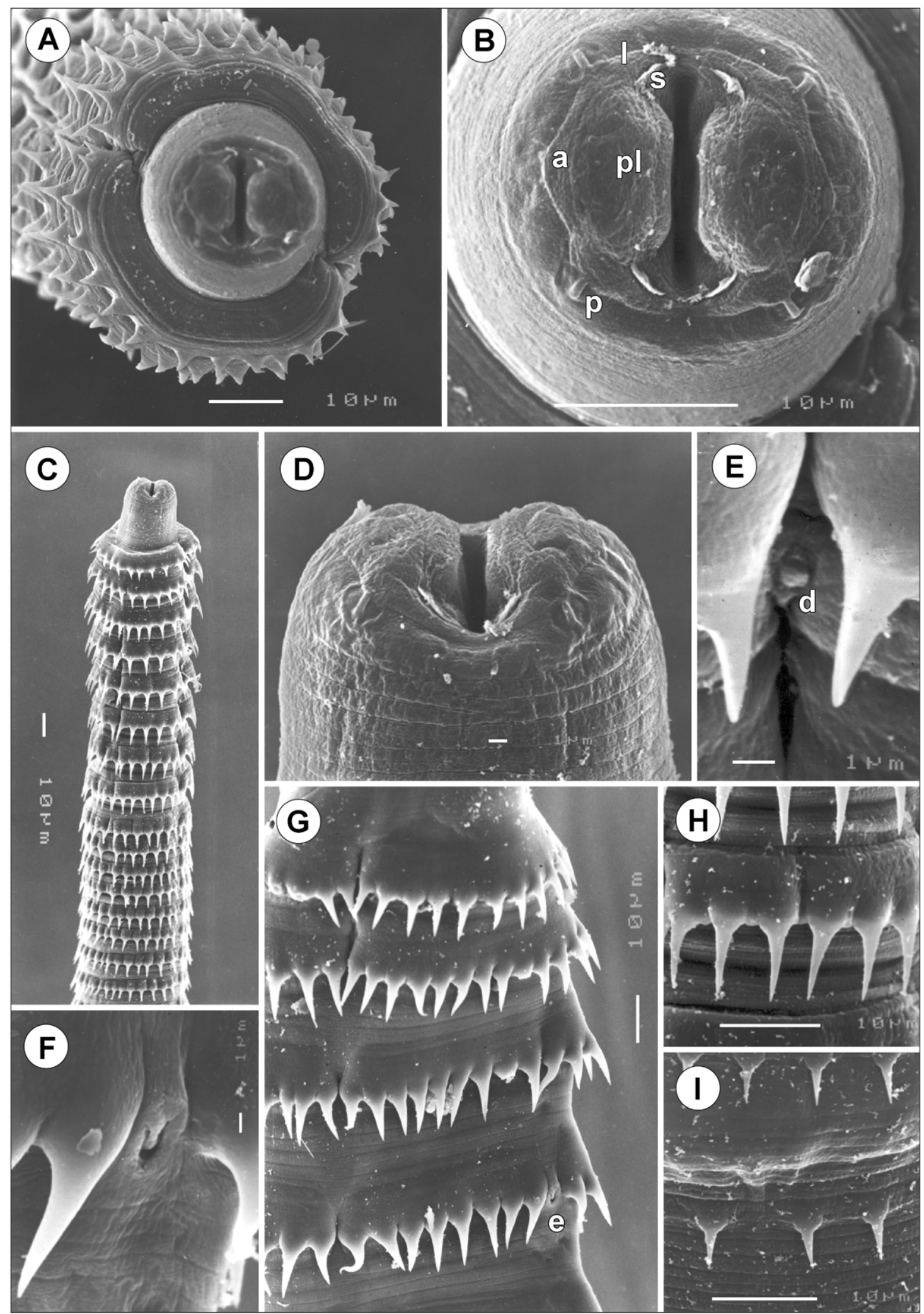

Fig. 2. Spinitectus petrowi Belous, 1965, scanning electron micrographs. A - cephalic end, apical view (focused on cuticular spines); $\mathbf{B}$ - mouth, apical view; $\mathbf{C}$ - anterior end of body, dorsoventral view; $\mathbf{D}$ - cephalic end, dorsoventral view; $\mathbf{E}$ - deirid; $\mathbf{F}$ - excretory pore; $\mathbf{G}$ - four anterior rings of cuticular spines with distinct location of excretory pore; $\mathbf{H}, \mathbf{I}$ - cuticular spines on anterior and posterior parts of body, respectively. a - amphid; d-deirid; 1 - labium; $\mathrm{p}$ - cephalic papilla; pl - pseudolabium; $\mathrm{s}-$ sublabium. 
basis of specimens collected from the stomach of the catfish Pelteobagrus fulvidraco of the Iman River (Amur River drainage system), Primorsk Territory, eastern Russia; the summary by the author ("avtoreferat") was printed in 1953, but this cannot be considered a publication in accordance with the International Code of Zoological Nomenclature (ICZN). Later, Roytman (1963) reported this species under the name Spinitectus petrovi Belous, 1952 from three species of bagrid catfishes, P. fulvidraco, Leiocassis brashnikowi (Berg) and Pseudobagrus ussuriensis (Dybowski), from the Zeya River (Amur R. basin) from the same region; the author gave a description based on newly collected specimens and provided measurements of this species from Belous' (1952) thesis. Later, Belous (1965) published the description and illustrations of this species from her thesis, naming it $S$. petrowi sp. nov. and giving its differential diagnosis. Finogenova (1971), reporting it as $S$. petrovi Belous, 1953, recorded it from the stomach and intestine of P. fulvidraco, P. ussuriensis, L. brashnikowi and Siniperca chuatsi (Basilewsky) from the Amur River basin (Amur and Zeya Rivers, Lakes Khivanda and Bolon), eastern Russia; she gave a somewhat more detailed description of this species and provided drawings of the anterior and male caudal ends. In the Key to Parasites of Freshwater Fishes of the USSR Fauna, Vismanis et al. (1987) reported it as S. petrovi Belous, 1952 , mentioning that it occurs in the intestine of catfishes of the family Bagridae in the Amur River basin.

Following the ICZN, it is clear that the name Spinitectus petrovi Belous, 1952 is invalid and unusable. The first published description of this species is that by Roytman (1963), referring to and containing data from Belous' (1952) thesis; however, because he did not provide any characters to differentiate this taxon (see Article 13.1.1 of the ICZN), the name $S$. petrovi Belous in Roytman, 1963 should be considered a nomen nudum according to the ICZN. Consequently, the valid name of this parasite is Spinitectus petrowi Belous, 1965.

Even though the original and subsequent descriptions of $S$. petrowi are rather incomplete, the morphological features and the host species of nematodes of the present material show that they belong to this species.

It is evident from the present study that $S$. petrowi exhibits some morphological features in which it differs considerably from the majority of its congeners. In particular it concerns its unusual mouth structure, that was not previously studied in this species. In contrast to the Spinitectus spp. in which the cephalic structures have been studied in detail, the pseudolabia of $S$. petrowi are large and rounded in an apical view and the submedian labia are poorly developed. A similar type of pseudolabia was described in Spinitectus sp. (reported as Prospinitectus sp.) from the catfish Pangasius sp. from the Mekong River in Laos (Moravec and Scholz 1991), in which the vestibule was markedly short as in $S$. petrowi, but the number of cuticular spines was much greater. The presence of a vestibule in $S$. petrowi was neither described nor illustrated by Belous (1965) and Roytman (1963); Finogenova (1971) mentioned the presence of a short vestibule in this species, but it is absent from her rather schematic drawing of the cephalic end.

Belous (1965) did not report the number of cuticular spines per ring in $S$. petrowi, whereas Roytman (1963) reported 22-24 and 34-36 spines in each ring (apparently not only in the first one) in the male and the female, respectively; Finogenova (1971) found 22-24 spines in the first ring in females. However, none of the above authors studied the number of spines in apical view and, therefore, their data need not be quite reliable. A few specimens (both males and females) examined by SEM in this study showed the presence of 29-37 spines in the first ring. SEM studies revealed a unique feature of S. petrowi, not previously reported for any Spinitectus species: the presence of the peculiar pairs of transversely oriented peg-like cuticular spines on the ventral side of the tail and of the preanal region in females.

As already illustrated by Belous (1965) and Finogenova (1971) and confirmed in this study, the male caudal alae are markedly broad as compared to those in many other Spinitectus spp. According to Belous (1965) and Roytman (1963), there are only 5 pairs of postanal papillae in this species, whereas Finogenova (1971) found 5-6 pairs, with the last pair being rudimentary or absent. However, as confirmed in this study, the last 3 pairs of these papillae are very small and difficult to observe with the light microscope; SEM examination shows clearly 6 pairs of postanal papillae in this species, followed by a pair of small phasmids, not previously reported in this species. The shape of spicules is rather unusual for Spinitectus: the left (large) spicule is conspicuously broad in a lateral view, as already illustrated by Belous (1965) and Finogenova (1971), but the right (small) spicule may seem to have a different shape depending on its position, appearing sometimes to be bifurcated at its proximal end (see Belous 1965, Finogenova 1971). The lengths of spicules found in the present study are within the ranges $(0.103-0.154 \mathrm{~mm}$ and $0.047-0.060 \mathrm{~mm}$ ) given by Finogenova (1971).

Belous (1965) observed the presence of a minute appendage with a cleft end situated on the tail tip of females; this was not mentioned by Roytman (1963) and Finogenova (1971). In specimens of the present material, this, variously shaped appendage was always present and can be considered a specific character of $S$. petrowi; however, it is inconspicuous and can be easily overlooked. A similar appendage on the female tail tip was described in Spinitectus tabascoensis Moravec, García-Magaña et Salgado-Maldonado, 2002 and S. macrospinosus Choudhury et Perryman, 2003 (see Moravec et al. 2002, Choudhury and Perryman 2003). 


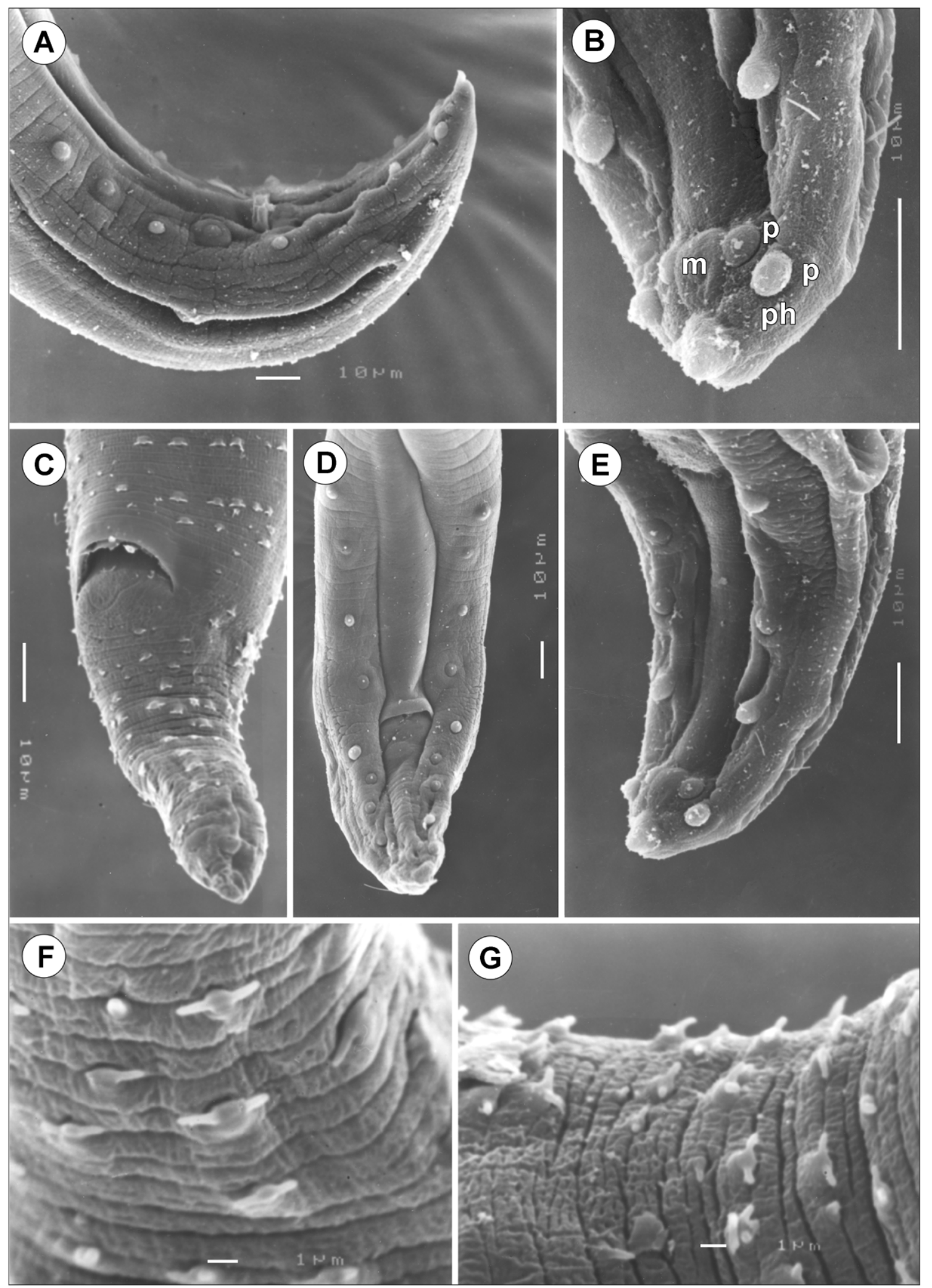

Fig. 3. Spinitectus petrowi Belous, 1965, scanning electron micrographs. A - posterior end of male, lateral view; B - tip of male tail, subventral view; $\mathbf{C}$ - tail of female, subventral view; $\mathbf{D}$ - posterior end of male, ventral view; $\mathbf{E}$ - tail of male, subventral view; F, G - double cuticular spines on ventral surface of female tail. $\mathrm{m}$ - median elevated area; $\mathrm{p}$ - caudal papilla; ph - phasmid. 
Wang et al. (1993) described Spinitectus bagri from the stomach and intestine of Pelteobagrus fulvidraco, Leiocassis crassilabris Günther, Mystus macropterus (Bleeker) and Pseudobagrus analis (Nichols) from the Wuling Mountain region (Provinces Guizhou and $\mathrm{Hu}-$ nan), China. It is characterized by a very short vestibule (the vestibule [called "pharynx"] is absent according to the description, but it is illustrated in their fig. 2b), presence of about 22-34 cuticular spines in anterior rings, lengths of spicules $0.119-0.161 \mathrm{~mm}$ and 0.046 $0.064 \mathrm{~mm}$ (the right spicule evidently confused with the left one), and the presence of allegedly four preanal and four postanal pairs of caudal papillae in the male. Although the description is rather incomplete, the general morphology of this species is practically identical with that of S. petrowi; some minor differences (e.g., in numbers of postanal papillae) are evidently due to inaccuracies in observations. Also the hosts are either identical or closely related. Therefore, S. bagri Wang, Wu et $\mathrm{Yu}$, 1993 is considered a junior synonym of $S$. petrowi Belous, 1965.

In 1997, $\mathrm{Yu}$ and Wang inadequately described another species, Spinitectus wulingensis, from the stomach and intestine of several species of fishes, Silurus asotus Linnaeus, Pelteobagrus vachellii (Richardson), Pseudobagrus analis, Leiocassis crassilabris, Mystus macropterus, Pseudobagrus ussuriensis, Odontobutis obscura (Temminck et Schlegel) and Ctenogobius sp., from rivers of the Wuling Mountains region (Provinces Guizhou, Hubei, Hunan and Sichuan), southwestern China. Also, the features of specimens reported as $S$. wulingensis appear very similar to those of $S$. petrowi, especially by their markedly short vestibule, character of cuticular spines, measurements of spicules, situation of the excretory pore and some other features. Since many hosts are bagrid catfishes belonging to the same genera or even species as those of $S$. petrowi, and both nematode species occur in the same region (e.g., in the Hubei Province as confirmed in this study), $S$. wulingensis should be considered a junior synonym of $S$. petrowi.

\section{Spinitectus gigi Fujita, 1927}

Figs. 4-6

Syn. Spinitectus clariasi Ky, 1971; S. ophicephali Ky, 1971; S. yuanjiangensis Wang, Wu et Yu, 1997.

Description. Small, whitish nematodes. Body elongate, its anterior part slender; body broadest at its posterior part. Cephalic end blunt, posterior end conical. Surface of body with transverse rings of spines; rings interrupted at both sides of body by lateral lines (Figs. 4D, 5D); some more posterior rings incomplete. First two rings of spines close to each other. First ring with 28-31 spines, 0.009 long (Figs. 4D, 5D). Largest spines present in anterior 2nd-4th ring; first 5-6 anterior rings of spines usually elevated; rings 2 to 7 fairly wide apart, followed by rings situated closely together (Fig. 5C); spines gradually diminishing posteriorly. Female body with spines up to posterior extremity (Fig. 4H, I); spina- tion of male finishes short distance anterior to level of proximal end of withdrawn left (large) spicule. Oral aperture oval, dorsoventrally elongated, surrounded by two low, large labia, one dorsal and one ventral, with broad base (Figs. 4C, 5A, B), forming dorsal and ventral margins of oral opening. One simple, narrow, bent sclerotized structure ("sublabium" in terminology of Margolis 1977), with a somewhat thickened free margin, attached by its base to inner surface of each labium. Lateral pseudolabia rather large, projecting anteriorly beyond labia. In apical view, flat inner parts of pseudolabia covering partly oral opening are somewhat dorsoventrally expanded, forming two (one laterodorsal and one lateroventral) extensions with sharp corners on each pseudolabium. Inner margins of both pseudolabia dorsoventrally straight, parallel to each other (Figs. 4C, 5A). Narrow, inner part of each pseudolabium continues posteriorly into thickened pulp bearing two elongate submedian cephalic papillae and small lateral amphids (Figs. 4C, 5A, B). Vestibule fairly long, thin-walled, without distinct anterior prostom in lateral view (Fig. 4B). Deirids not found. Oesophagus clearly divided into anterior muscular and much longer and somewhat wider posterior portion; length ratio of both portions $1: 2.3-$ 3.6. Nerve ring encircles muscular oesophagus at level between second and third rings of spines. Excretory pore situated at level of fourth ring of spines (Figs. 4B, $5 \mathrm{E})$. Tails of both sexes conical. Males smaller than gravid females.

Male (3 specimens from $P$. fulvidraco; measurements of 1 specimen from C. fuscus in parentheses): Length of body 4.842-6.433 (5.209), maximum width $0.109-0.136$ (0.082). Maximum length of spines 0.009 (0.012). First ring of spines situated 0.105-0.150 (0.111) from anterior extremity. Length of vestibule $0.057-0.180$ (0.054). Prostom indistinct (0.015 long, 0.018 wide). Entire oesophagus $1.755-1.770$ (1.134) long, representing $27-37 \%$ (22\%) of whole body length. Muscular oesophagus $0.381-0.525$ (0.294) long, $0.018-$ 0.024 (0.015) wide; glandular oesophagus 1.230-1.389 (0.840) long, 0.048-0.063 (0.045) wide; length ratio of both parts of oesophagus $1: 2.3-3.6(1: 2.9)$. Nerve ring and excretory pore $0.135-0.153(0.156)$ and 0.219 0.231 (0.216), respectively, from anterior extremity. Posterior end of body ventrally curved, provided with well-developed subventral alae reaching end of tail. Ventral precloacal ridges (area rugosa) well developed, formed by four longitudinal rows of elevated longitudinal cuticular outgrowths (Figs. 4F, 5G). Preanal papillae: 4 pairs of subventral pedunculate, equally spaced papillae present. Postanal papillae: 5 pairs of subventral papillae and 1 pair of ventral papillae situated between last two pairs of subventrals (Figs. 4F, 5H, 6). Pair of small ventral phasmids located just posterior to last pair of postanal papillae. Large (left) spicule narrow, 0.6840.705 (0.690) long, with rounded tip; length of its shaft $0.333-0.354$ (0.297) (49-50\% [43\%] of whole spicule 

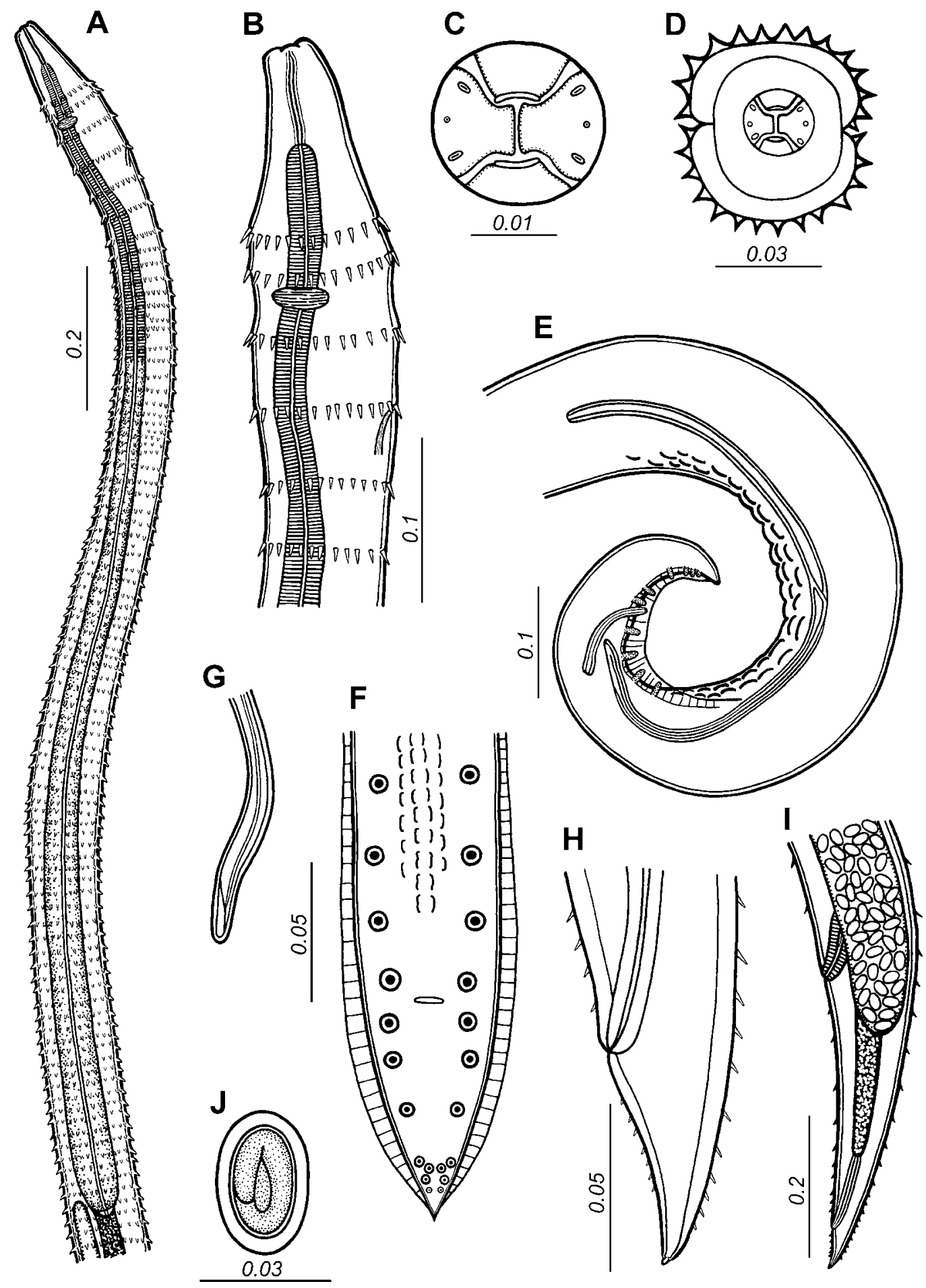

Fig. 4. Spinitectus gigi Fujita, 1927. A - anterior end of male, lateral view; B - same, larger magnification; C - mouth, apical view (reconstructed from scanning electron micrograph); D - cephalic end, apical view (reconstructed from scanning electron micrograph); E, F - posterior end of male, lateral and ventral views; $\mathbf{G}$ - distal end of large spicule, lateral view; $\mathbf{H}$ - tail of gravid female, lateral view; I - posterior end of gravid female, lateral view; J - egg. Scale bars in mm. (A-G - specimens from Pelteobagrus fulvidraco; J-I - specimens from Clarias fuscus.) 
length). Small (right) spicule narrow, 0.093-0.096 (0.102) long (Fig. 4E). Length ratio of spicules $1: 7.3-$ $7.4(1: 6.8)$. Tail $0.090-0.114(0.072)$ long, with sharply pointed tip (Figs. 4F, 5G, H).

Female ( 3 gravid specimens from $C$. fuscus): Length of body 7.548-8.255, maximum width $0.150-0.163$. Maximum length of spines 0.012. First ring of spines $0.120-0.132$ from anterior extremity. Length of vestibule including prostom $0.066-0.072$; prostom 0.015 long and 0.018 wide. Entire oesophagus 1.284-1.314 long, representing $16-17 \%$ of whole body length. Muscular oesophagus $0.285-0.354$ long, $0.015-0.018$ wide; glandular oesophagus 0.930-1.029 long, 0.042 wide; length ratio of both parts of oesophagus 1 : 2.6-3.6. Nerve ring and excretory pore $0.162-0.168$ and $0.228-$ 0.246 , respectively, from anterior extremity. Vulva not elevated, situated in posterior part of body at short distance anterior to anus, 7.223-7.820 from anterior extremity (at 95-96\% of body length) (Fig. 4I). Vagina muscular, directed anteriorly from vulva. Amphidelphic. Posterior end of uterus at short distance posterior to vulva. Fully developed eggs in uterus oval, thickwalled, smooth, larvated; size $(\mathrm{n}=10) 0.033-0.036 \times$ $0.021-0.022$; thickness of their wall $0.004-0.005$. Tail 0.054-0.057 long, covered by simple cuticular spines, with pointed tip.

H o s t s : Yellow catfish Pelteobagrus fulvidraco (Richardson) and whitespotted clarias Clarias fuscus (Lacépède) (Bagridae and Clariidae, respectively, both Siluriformes).

$\mathrm{S}$ it e of infection: Intestine (in P. fulvidraco).

L o c a 1 i t i e s : Liangzihu Lake (Yangtze River basin),

Hubei Province, central China (P. fulvidraco, collected 18 September 2002); and Nanhai (Yangtze River basin?), JiuKiang, Jiangxi Province, southern China (C. fuscus, collected 7 September 1986).

Prevalence and intensity: P. fulvidraco: $10 \%(2$ fish infected / 20 fish examined); 2 and 3 specimens (males and a juvenile female). C. fuscus: no data available.

Comments. This species was inadequately described by Fujita $(1927 \mathrm{a}, \mathrm{b})$ from the only available male collected in the intestine of Pseudobagrus nudiceps Sauvage of Lake Biwa in Japan. Later, Yamaguti (1935) redescribed $S$. gigi on the basis of two males and two gravid females collected from the stomach of the same host species from Japan (locality not given) and mentioned some mistakes in the original species description by Fujita (1927a) concerning the number and arrangement of caudal papillae and the character of spicules: Fujita (1927a, b) erroneously reported the presence of only three pairs of caudal papillae (two of them being preanal) but illustrated seven pairs (four preanal and three postanal), and he described spicules to be similar and $1.27 \mathrm{~mm}$ long.

Belous (1965) recorded $S$. gigi from the stomach of Pelteobagrus fulvidraco from the Iman River (Amur River drainage system), Primorsk Territory, eastern Russia (prevalence $8 \%$, intensity $1-3$ ), but she did not mention its morphology. However, some morphological data from her unpublished thesis (Belous 1952), based on one young male and one immature female, were provided by Skryabin et al. (1967).

From China, Spinitectus gigi was reported by Chen (1973) and Wang (1984) from P. fulvidraco from Hubei and Fujian Provinces, respectively; the former also gave a brief description in Chinese and illustrated the anterior end of body and male and female caudal ends. Later, $S$. gigi was listed from the same host species in Bao'an Lake, Hubei Province, by Wu et al. (1991). In the monographs by Pan et al. (1990) and Zhang et al. (1999), $S$. gigi was mentioned as one of Spinitectus spp. occurring in China, which was apparently based on records by previous authors.

As already stated by Moravec and Sey (1988), the morphology of $S$. gigi is insufficiently known and the existing descriptions are very incomplete, making the separation of this species from related congeners difficult. The identification of nematodes of the present material is mainly based on their morphological and biometrical similarity to this species, as redescribed by Yamaguti (1935), the host types, and the geographical distribution.

An important feature in Spinitectus spp. is generally considered to be the number and distribution of cuticular spines on the body, even though the number of spines per ring may exhibit a high degree of intraspecific variability in some species (Moravec 1996). The number of spines in the first ring in $S$. gigi was reported to be $22-30$, about 25 and $22-26$ by Yamaguti (1935), Belous (1952) and Chen (1973), respectively; however, none of these authors studied the spines in an apical view, so that the reported numbers need not be exact. In the present study by SEM, these spines ranged within 28-31 in specimens collected from both $P$. fulvidraco and C.fuscus; it also shows for the first time that $S$. gigi belongs to the morphological group of species characterized by anterior rings of spines divided into two (dorsolateral and ventrolateral) sectors. Characteristic features of this species are the first two rings of spines located close to each other, relatively long distances between the 2 nd -7 th rings, and the body spination extending posteriorly to the tail in females.

The exact structure of the cephalic end was not previously studied in $S$. gigi; the present SEM study shows that the structure of mouth is more or less typical of the Spinitectus spp. parasitic in freshwater fishes (Petter 1984). According to Moravec (1979), one of the most stable taxonomic features in Spinitectus spp. is the location of the excretory pore in relation to anterior rings of spines; unfortunately, this was not described for the majority of Spinitectus spp., including S. gigi. In the latter species, as found in this study, the location of the excretory pore at the level of the fourth ring of spines is typical of many species parasitic in Eurasian and African freshwater fishes. 

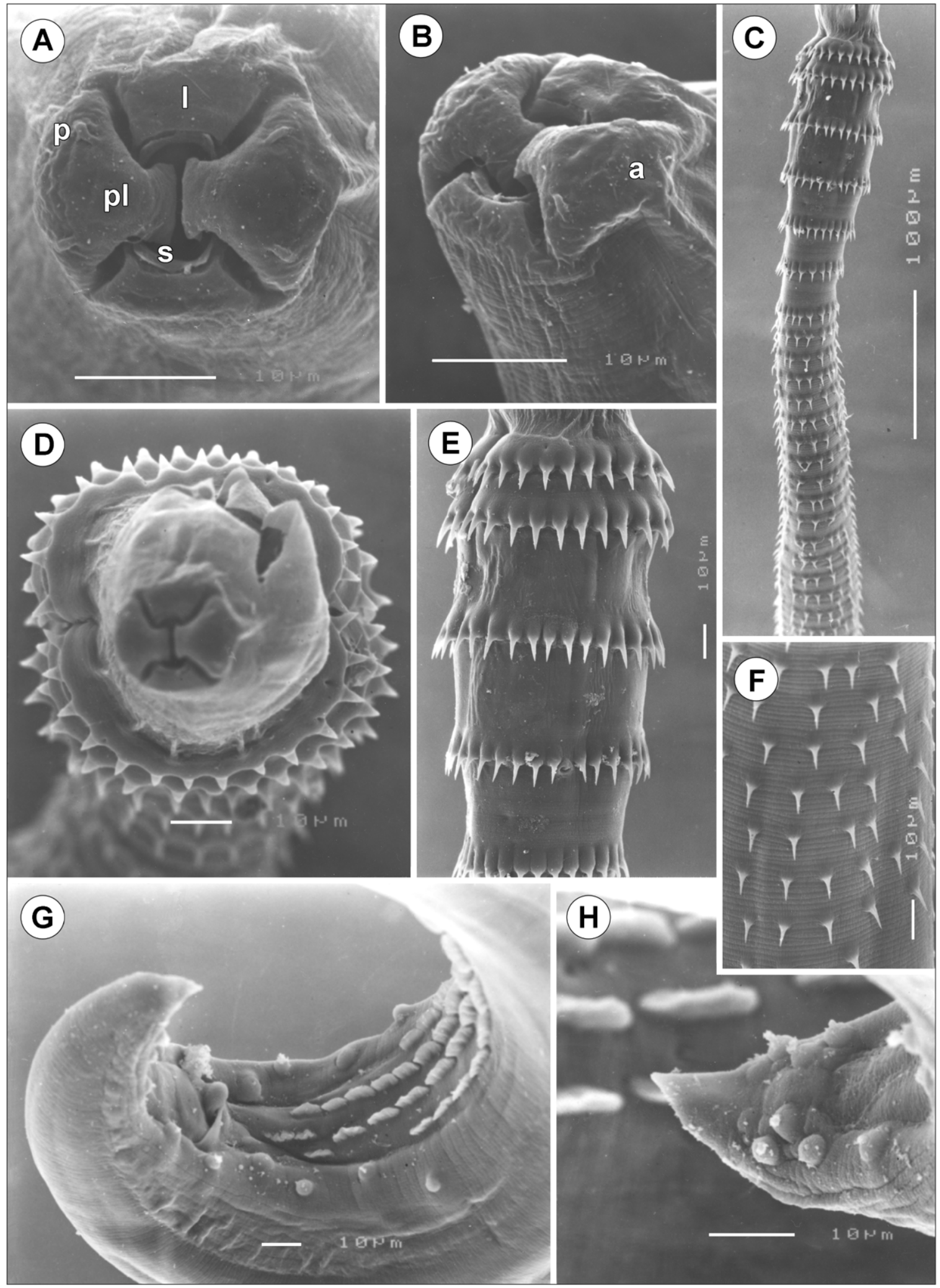

Fig. 5. Spinitectus gigi Fujita, 1927 from Pelteobagrus fulvidraco, scanning electron micrographs. A, B - cephalic end, apical and sublateral views; $\mathbf{C}$ - rows of cuticular spines on anterior end of male; $\mathbf{D}$ - cephalic end of male, apical view (focused on cuticular spines); $\mathbf{E}$ - four anterior rings of spines with distinct location of excretory pore, ventral view; $\mathbf{F}$ - cuticular spines on posterior part of body; $\mathbf{G}$ - posterior end of male, sublateral view; $\mathbf{H}$ - tip of male tail, ventral view. a - amphid; 1 - labium; $p$ - cephalic papilla; $\mathrm{pl}$ - pseudolabium; s - sublabium. 


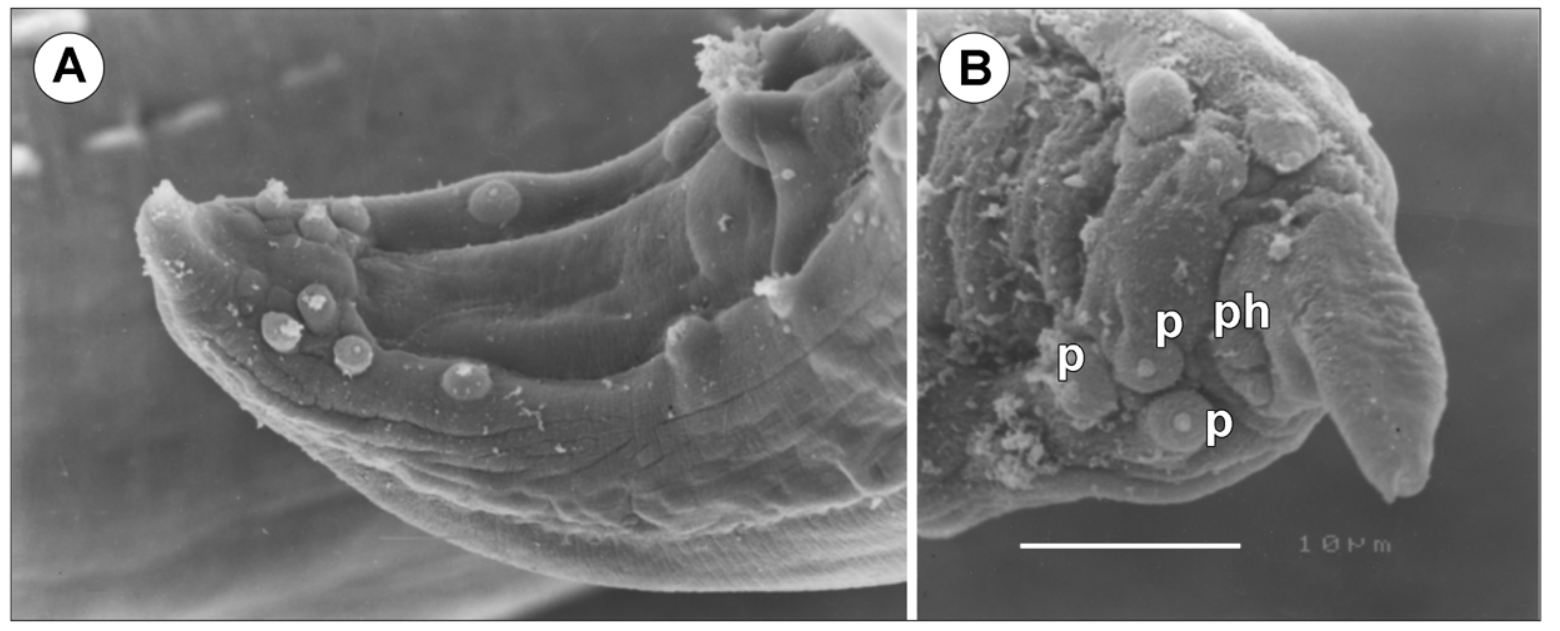

Fig. 6. Spinitectus gigi Fujita, 1927, scanning electron micrographs. A - tail of male, subventral view; B - tip of male tail, ventral view. (A - specimen from Pelteobagrus fulvidraco, E - specimen from Clarias fuscus.) $\mathrm{p}$ - caudal papilla; ph - phasmid.

Yamaguti (1935) reported four pairs of preanal and six pairs of postanal caudal papillae in the male of $S$. gigi, whereas Belous (1962) observed four pairs of preanals, one pair of adanals and four pairs of postanals in this species (none of them studied the papillae in ventral view). The present SEM study has shown clearly the number and distribution of the papillae (4 pairs of preanals and 6 of postanals) in this species, which is typical of some other congeneric species, and previously unreported phasmids.

As already mentioned by Yamaguti (1935), the spicules of $S$. gigi were described erroneously in the original description by Fujita (1927a, b). Yamaguti (1935) gave the length of the left spicule to be $0.8-0.9 \mathrm{~mm}$ and that of the right spicule $0.11-0.12 \mathrm{~mm}$, whereas Belous (1962) reported $0.550 \mathrm{~mm}$ and $0.082 \mathrm{~mm}$, respectively; in the present material, the spicules were 0.684-0.705 $\mathrm{mm}$ and $0.093-0.102 \mathrm{~mm}$ long. As pointed out by Moravec (1979) in Spinitectus inermis (Zeder, 1800), a parasite of European eels, there may be considerable intraspecific differences in the length of the left spicule.

From freshwater fishes of the Oriental Region, many Spinitectus spp. were described on the basis of features subjecting to a considerable individual variability; from this reason, they cannot be diagnosed at present (Petter 1979, Moravec and Sey 1988). Some of them may be identical with $S$. gigi. Ky (1971) inadequately described two Spinitectus spp., S. clariasi from Clarias fuscus and S. ophicephali from Channa maculata (Lacépède) from North Vietnam (Hanoi). Later, Moravec and Sey (1988) redescribed $S$. ophicephali from specimens newly collected from its type host species (C. maculata) and from Pelteobagrus fulvidraco in North Vietnam (Hanoi), showing some mistakes in the original description (e.g., the lengths of spicules and numbers of male caudal papillae) and mentioning that this species is probably identical with $S$. gigi; however, due to the insufficiently known morphology of $S$. gigi at that time, they retained
S. ophicephali as an independent species. The present study shows that the morphological features of both species are identical and, therefore, S. ophicephali Ky, 1971 is considered a junior synonym of $S$. gigi. It is well known that some Spinitectus spp. may parasitize as adults fishes belonging to different orders. Also $S$. clariasi, a species collected from the same locality (Ko-Bi reservoir, Hanoi) as $S$. ophicephali, should be considered a junior synonym of S. gigi. Ky (1971) distinguished it from $S$. gigi by the distance of the first ring of cuticular spines from the anterior extremity, but this is identical in the latter species, as seen from this paper; the spicules and male caudal papillae were probably erroneously described as in the case of S. ophicephali.

Wang et al. (1993) described Spinitectus yuanjiangensis from the stomach and intestine of Silurus asotus (Siluridae), Pseudobagrus analis (Bagridae) and Coreoperca whiteheadi (Boulenger) (Percichthyidae), distinguishing it from $S$. gigi by allegedly more numerous cuticular spines (about 28-30) per ring, a relatively short (0.496-0.587 mm long) left spicule (the right and the left spicule were evidently confused), and the vulva situated relatively far from the posterior extremity. The body length was not given. However, in fact, the number of cuticular spines is identical with that in $S$. gigi and also the length of the larger spicule is almost within the range of the latter species (see, e.g., Belous 1952). Apparently, the number (5) of pairs of postanal papillae in $S$. yuanjiangensis was given inaccurately, because the male caudal end was studied only in a lateral view (the most posterior pairs of small papillae are indistinct in this position); it is highly probable that the number of postanal papillae is identical in both species. Consequently, the only difference by which this species would differ from $S$. gigi is the location of the vulva. However, taking into account that more than one Spinitectus species may occur concurrently in the same host fish, the conspecificity of males and females of $S$. yuanjiangensis 
can be questioned. The position of the vulva as reported for $S$. yuanjiangensis is typical of $S$. petrowi, which cooccurs with $S$. gigi, for example in Pelteobagrus fulvidraco, as pointed out in this paper. Since the holotype male of $S$. yuanjiangensis seems to be identical with $S$. gigi, the former should be considered a junior synonym of the latter.

Acknowledgements. The authors thank Luo Haiyan of the Institute of Hydrobiology, Chinese Academy of Sciences, for her assistance in obtaining fishes. Thanks are also due to the staff of the Laboratory of Electron Microscopy of the Institute of Parasitology, ASCR, for their technical assistance and to Irena Husáková of the Department of Helminthology from the same institute for her help with the preparation of illustrations. This study was supported by the grant no. ME 424 from the Ministry of Education, Youth and Sports of the Czech Republic, and by the grant no. 30025035 from the National Natural Science Foundation of China.

\section{REFERENCES}

BELOUS E.V. 1952: [Parasitic worms of freshwater vertebrates of the Primorsk Territory.] C.Sc. thesis, VIGIS, Moscow (summary by the author printed in 1953). (In Russian.)

BELOUS E.V. 1965: [Nematodes of freshwater fishes of the Primorsk Territory.] Sb. "Paraziticheskie Chervi Domashnikh i Dikikh Zhivotnykh", Vladivostok, pp. 48-65. (In Russian.)

CHEN C.-L. (Ed.) 1973: [An illustrated guide to the fish diseases and causative pathogenic fauna and flora in the Hubei Province.] Science Press, Beijing, 456 pp. (In Chinese.)

CHOUDHURY A., PERRYMAN B.J. 2003: Spinitectus macrospinosus n. sp. (Nematoda: Cystidicolidae) from the channel catfish Ictalurus punctatus in southern Manitoba and its distribution in other Ictalurus spp. J. Parasitol. 89: 782-791.

FINOGENOVA S.P. 1971: [Round worms of fishes of the Amur River basin.] Parazitol. Sb., Tr. Zool. Inst. Akad. Nauk USSR 25: 140-164. (In Russian.)

FROESE R., PAULY D. (Eds.) 2003: FishBase. World Wide Web electronic publication, www.fishbase.org, version 04 February 2003.

FUJITA T. 1927a: [Parasitic worms from fishes of Lake Biwa. II.] Dobutsugaku Zasshi 39: 159-160. (In Japanese.)

FUJITA T. 1927b: On new species of nematodes from fishes of Lake Biwa. Jpn. J. Zool. 1: 169-176.

KY Kh. 1971: Some new nematodes from freshwater fishes of North Vietnam. Parazitologiya 5: 241-250. (In Russian, Engl. summary.)

MARGOLIS L. 1977: Caballeronema gen. nov. for Metabronema wardlei Smedley, 1934 (Nematoda, Spiruroidea) from the marine fish Scorpaenichthys marmoratus from the Pacific coast of Canada. In: Excerta Parasitológica en memoria del doctor Eduardo Caballero y Caballero, Instituto de Biología, Universidad Nacional Autónoma de México, Publicaciones especiales 4, pp. 447-454.

MORAVEC F. 1979: Redescription of the nematode Spinitectus inermis parasitic in eels, Anguilla anguilla, of Europe. Acta Soc. Zool. Bohemoslov. 43: 35-42.

MORAVEC F. 1996: Some new data on the morphology of Spinitectus inermis (Nematoda: Cystidicolidae), a rare parasite of eels, as revealed by SEM. Parasite 3: 169-174.

MORAVEC F., GARCÍA-MAGAÑA L., SALGADO-MALDONADO G. 2002: Spinitectus tabascoensis sp. nov. (Nematoda, Cystidicolidae) from Ictalurus furcatus (Pisces) in southeastern Mexico. Acta Parasitol. 47: 224-227.
MORAVEC F., NIE P. 2002: Observations on two species of phyllodistomes (Trematoda: Gorgoderidae) from fishes of the Hubei Province, central China, with an erection of Neophyllodistomum gen. n. Helminthologia 39: 221-225.

MORAVEC F., NIE P., SCHOLZ T., WANG G. 2003a: Some trematodes and cestodes of fishes mainly from Hubei Province, central China. Acta Soc. Zool. Bohem. 67: 161174.

MORAVEC F., NIE P., WANG G. 2003b: Some nematodes of fishes from central China, with the redescription of Procamallanus (Spirocamallanus) fulvidraconis (Camallanidae). Folia Parasitol. 50: 220-230.

MORAVEC F., NIE P., WANG G. 2003c: Observations on some acanthocephalans of fishes from Hubei Province, central China. Acta Soc. Zool. Bohem. 67: 213-224.

MORAVEC F., SCHOLZ T. 1991: Observations on some nematodes parasitic in freshwater fishes in Laos. Folia Parasitol. 38: 163-178+8 Plts.

MORAVEC F., SEY O. 1988: Nematodes of freshwater fishes from North Vietnam. Part 1. Camallanoidea and Habronematoidea. Acta Soc. Zool. Bohemoslov. 52: 128-148.

MORAVEC F., WANG G. 2002: Dentiphilometra monopteri n. gen., n. sp. (Nematoda: Philometridae) from the abdominal cavity of the ricefield eel Monopterus albus in China. J. Parasitol. 88: 961-966.

PAN J.H., ZHANG J.Y., LI Z.C. (Eds.) 1990: [Fish Parasitology.] Science Press, Beijing, 443 pp. +23 Plts. (In Chinese.)

PETTER A.-J. 1979: Trois nématodes parasites de poissons en Malaisie. Bull. Mus. Natl. Hist. Nat., Paris, $4^{\mathrm{e}}$ sér., sect. A, 1: 585-596.

PETTER A.-J. 1984: Nématodes de poissons du Paraguay II. Habronematoidea (Spirurida). Description de 4 espèces nouvelles de la famille des Cystidicolidae. Rev. Suisse Zool. 91: 935-952.

ROYTMAN V.A. 1963: [Nematodes of fishes of the Zeya River basin.] Tr. GELAN 13: 253-300. (In Russian.)

SKRYABIN K.I., SOBOLEV A.A., IVASHKIN V.M. 1967: [Spirurata of Animals and Man and the Diseases Caused by Them. Part 4. Thelazioidea.] Osnovy nematodologii 16. Nauka, Moscow, 624 pp. (In Russian.)

VISMANIS K.O., LOMAKIN V.V., ROYTMAN V.A., SEMENOVA M.K., TROFIMENKO V.Ya. 1987: Nemathelminthes. In: O.N. Bauer (Ed.), [Key to Parasites of Freshwater Fishes of the USSR Fauna, Vol. 3 Parasitic Metazoans, Part 2.] Nauka, Leningrad, pp. 187-310. (In Russian.) 
WANG P.-Q. 1984: Descriptions of three new species and a list of parasitic nematodes from vertebrates in Fujian Province. Wuyi Sci. J. 4: 113-132. (In Chinese, Engl. summary.)

WANG G., WU H., YU Y. 1993: Two new species of Spinitectus (parasitic nematodes) from fish. Trans. Res. Fish Dis. 1: 123-128. (In Chinese, Engl. summary.)

WU H., LI L., FENG W., YAO W., LIU J., YU Y. 1991: [A preliminary study of the fish parasitic fauna of the Bao'an Lake. In: C. Hu and X. Huang (Eds.), Collected Papers on the Fishery Ecology and Exploitation Technology of

Received 26 January 2004
Bao'an Lake.] Science Press, Beijing, pp. 160-171. (In Chinese.)

YAMAGUTI S. 1935: Studies on the helminth fauna of Japan. Part 9. Nematodes of fishes, 1. Jpn. J. Zool. 6: 337-386.

YU Y., WANG G.T. 1997: Notes on the nematodes, including several new species, from fishes from Wuling Mountains area. In: S. Daxiang (Ed.), Invertebrates of Wuling Mountains Area, Southwestern China. Science Press, Beijing, pp. 240-252. (In Chinese, Engl. summary.)

ZHANG J.Y., QIU Z.Z., DING X.J. 1999: [Parasites and Parasitic Diseases of Fishes.] Science Press, Beijing, 735 pp. (In Chinese.)

Accepted 16 May 2004 